\title{
SUCROSE DENSITY-GRADIENT ISOLATION METHOD INTENDED FOR IMPROVEMENT OF SAMPLE PURITY PRIOR TO AMPLIFICATION OF GIARDIA B-GIARDIN GENE
} By

AZZA I. EL- ADAWAY ${ }^{1}$, MARWA A. ELMALLAWNAY ${ }^{1 *}$, REHAM K. M. NAHNOUSH ${ }^{1}$ AND OMAYMA M. HASSANIN ${ }^{2}$

Parasitology ${ }^{1}$, Faculty of Medicine, Cairo University, and Department of Molecular Biology ${ }^{2}$, Medical Research Center, Faculty of Medicine, Ain-Shams University Hospitals, Cairo 11566 ( ${ }^{*}$ Correspondence: mamallawany@hotmail.com)

\section{Abstract}

PCR-based methods have been widely used for detection of Giardia in stool. The sensitivity and hence degree of success of the molecular tool depends on many factors including efficiency of DNA extraction method, in addition to the degree of purity which necessitate removal of a great number of inhibitors from the stool samples. Therefore, Sucrose densitygradient isolation method was assessed in this study to be applied prior to nucleic acid extraction and amplification of Giardia duodenalis in stool samples. The methods: Two different approaches were applied in this study to amplify $\beta$-giardin gene specific for Giardia duodenalis (syn. G. intestinalis, G. lamblia) using 30 microscopically Giardia positive fecal samples. A) Direct nucleic acid extraction using QIAamp Mini spin columns B) Sucrose densitygradient isolation method prior to DNA extraction using the same extraction Kit. The property of the extracted samples was determined by Spectrophotometric analysis at 260 and at 280 $\mathrm{nm}$.

The results showed that in spite of the significant larger amount of nucleic acid obtained by method (A) versus method (B), more pure form of DNA was encountered by method (B) than method (A). Purity encountered by method (A) reflected protein contamination of the samples. Following nested PCR reaction, 28 samples of group (B) showed positive bands $(511 \mathrm{pb})$, while 8 samples from group (A) failed to be amplified.

Key words: Giardia duodenalis- Sucrose density- purity- PCR.

\section{Introduction}

Giardia lamblia (also known as Giardia duodenalis and Giardia intestinalis) is an intestinal protozoan, well-known to initiate diarrheal disease in humans (Caccio et al, 2005; Read et al, 2004; Plutzer et al, 2010). It is reported to be the commonest enteroparasite in parasitological surveys, accomplished in both developed and developing nations (David et al, 2011). Most infected people remain asymptomatic, thus promote spread of such protozoal infection. In general, infection can lead to a wide range of clinical manifestations, including watery diarrhea, abdominal discomfort and bloating. In severe cases, malnutrition, malabsorption and disruption of the weight curve in children may be observed (Escobedo and Cimerman, 2007). Long-established diag- nostic methods usually rely on detection of unstained or stained Giardia cysts or trophozoites in stool using light microscopy. However, variability in excreting this parasite may lead to misdiagnosis of many cases, especially when a single sample used to screen for the infection. So, repetitive samplings may be essential, in addition to concentration techniques for truthful diagnosis. These multiple procedural operational steps, yet of low sensitivity and are indeed time consuming. Moreover, lack of genetic characterization, which is vital for recent epidemiological studies, adds another obstacle of using the conventional diagnostic techniques (Chakarova, 2010; Goni et al, 2012; Nahavandi et al, 2011).

The molecular techniques are emerged as substitution methods to pass up the limita 
tions of traditional procedures. PCR- constructed techniques are reported to have better sensitivities than microscopy to diagnose Giardia infection directly from stool samples (Gomes et al, 2004). Many protocols to extract and amplify $G$. intestinalis DNA had been published. Still, the presence of many of PCR inhibitors in feces and degraded DNA remains among major challenges for achievement of successful PCR reaction from fecal material (Caccio and Ryan, 2008; Nantavisai et al, 2007; Traub et al, 2005). Cyst concentration prior to DNA extraction had been adopted by many protocols. Yet, the optimal combination of molecular protocols for successful DNA extraction and amplification of Giardia lamblia in human feces has not been identified and no ideal protocol has been established (Caccio et al, 2005; Nantavisai et al, 2007; Read et al, 2004; Pelayo et al, 2008).

The purpose of the present study was to assess the efficacy of sucrose density-gradient isolation method (when applied prior to nucleic acid extraction) in improvement of amplification process of Giardia duodenalis in stool samples.

\section{Materials and Methods}

Study design and sample collection: A cross sectional study was carried out on 220 patients with gastrointestinal symptoms attending the outpatient clinics of Abou-ElReish Hospitals, Faculty of Medicine, Cairo University. Fresh fecal specimens were collected from all cases in clean plastic cups. Stool samples were examined by light microscopy using Lugol's iodine-stained wet mount and formalin ethyl acetate concentration techniques. The 30 stool samples were confirmed to be G. lamblia positive samples.

Sucrose density-gradient isolation method: About half gram of stool was diluted with distilled water and filtered through double layers of gauze to remove the coarse material. The filtrate was centrifuged at $800 \times \mathrm{g}$ for $5 \mathrm{~min}$. The supernatant was eliminated. The homogenized pellet of each stool sample was vortexed and divided into two portions.
The first portion was placed in eppindorph tubes and represented GA. The second portion was placed in $15 \mathrm{ml}$ falcon tubes and Sucrose density-gradient isolation was applied (Clark and Diamond, 2002) with some modifications and represented GB. To specify, stool samples were diluted 1:10 (vol/vol) in distilled water and diluted stool was vortexed. $5 \mathrm{ml}$ of the resultant stool pellet was placed onto $10 \mathrm{ml}$ of $1 \mathrm{M}$ sucrose in a $15 \mathrm{ml}$ falcon tubes. Spin at 450x g for 5 min was performed. The supernatant was pipetted off and spined at 450xg for $5 \mathrm{~min}$. The pellet was resuspended in $2.5 \mathrm{ml}$ of distilled water and layered on top of $10 \mathrm{ml}$ of $0.5 \mathrm{M}$ sucrose in a $15-\mathrm{ml}$ centrifuge tube. Spin at $450 \mathrm{xg}$ for 5 min was again performed. With a Pasteur pipette, the bottom $1 \mathrm{ml}$ of liquid was removed and place in a clean centrifuge tube of which $200 \mu \mathrm{l}$ were put ineppindorph tubes representing samples of GB. All samples belonging to GA and GB were stored at $20^{\circ} \mathrm{C}$ without preservatives until DNA extraction was performed.

Extraction of DNA: Prior to DNA extraction, samples of both groups (A) and (B) were subjected to five freeze/thaw cycles; 2 min in liquid nitrogen followed by $2 \mathrm{~min}$ in a $98^{\circ} \mathrm{C}$ water bath. Thus, the genomic DNA of G. lamblia was extracted using QIAamp Mini spin columns according to the manufacturer's instructions with the modification where suspension containing ASL and stool was heated for $60 \mathrm{~min}$ at $90^{\circ} \mathrm{C}$.

DNA quality and quantity assessment: To evaluate efficiency of both methods (A) and (B), the amplicon concentration generated in the two groups $(\mu \mathrm{g} / \mu \mathrm{l})$ was measured using a NanoDrop ${ }^{\circledR}$ Spectrophotometer and $0.7 \%$ $(\mathrm{w} / \mathrm{v})$ agarose gel, looking for the absorbance peak at $260 \mathrm{~nm}$ and at $280 \mathrm{~nm}$. A 260/ 280 absorbance ratio was then calculated.

PCR amplification: The amplification of Giardia $\beta$-giardin gene was performed for both groups (A) and (B) using a nested PCR protocol as previously described by Lalle et al. (2005). In the primary PCR reaction, a $753 \mathrm{bp}$ fragment was amplified using the 
forward primer G7 (5'-AAGCCCGACGAC CTCACCCGCAGTGC- 3') and the reverse primer G759 (5'GAGGCCGCCCTGGATC TTCGAGACGAC-3'). In sequential nested PCR reaction, a 511 bp fragment was amplified using the forward primer 5- GAACGAACGAGATCGAGGTCCG- 3 and the reverse primer 5-CTCGACGAGCTTCGTG TT-3'. In all cases of both groups, the PCR mix consisted of $1 \mathrm{X}$ buffer containing 1.5 $\mathrm{mM} \mathrm{MgCl} 2,200 \mathrm{mM}$ of each dNTP, 10 pmol of each primer, 2.5 units of AmpliTaq Gold DNA polymerase (Applied Biosystems, Monza, Italy), and $1-5 \mathrm{ml}$ of purified DNA in a final volume of $50 \mathrm{ml}$. PCR was performed as follows: after an initial denaturation step of $15 \mathrm{~min}$ at $95^{\circ} \mathrm{C}$, a set of 35 cycles was run, each consisting of $30 \mathrm{sec}$ at $95^{\circ} \mathrm{C}, 30 \mathrm{sec}$ of annealing $\left(65^{\circ} \mathrm{C}\right.$ for the primary $\beta$-giardin PCR, $55^{\circ} \mathrm{C}$ for the nested $\beta$ giardin) and $60 \mathrm{sec}$ at $72^{\circ} \mathrm{C}$, followed by a final extension of $7 \mathrm{~min}$ at $72^{\circ} \mathrm{C}$. PCR products were electrophoresed on ethidium bromide-stained $1 \%$ agarose gel.

Statistical analysis: Data were analyzed using statistical package of social science (SPSS) software; version "PASW ${ }^{\circledR}$ Statistics 18 " (SPSS Inc., Chicago, IL). Numerical data were expressed as mean and standard deviation. Qualitative data were expressed as frequency and percentage. Chi-square test (Fisher's exact test) was used to examine relation between qualitative variables. For quantitative data, comparison between groups was done using Mann-Whitney test (nonparametric t-test). $\mathrm{P}<0.05$ denoted significant difference, $<0.001$ a highly significant difference and $>0.05$ was not significant.

\section{Results}

Comparing samples of both groups, GA was heavily contaminated with bacteria and fecal detritus (Fig. 1a). This heavy contamination was reduced on using Sucrose density-gradient concentration technique employed in GB, as it was able to get rid of particles that are denser and larger than $G i$ ardia cysts. Less dense particles and bacteria were retained with cysts after applying 1 mole of sucrose. Many of the contaminants were removed at the ends of all steps and the cysts were recovered finally (Fig. 1b).

As regard the quantity of the extracted DNA from the 2 methods, significant larger amount of nucleic acid was obtained by method (A) $73 \pm 11 \mu \mathrm{g} / \mu 1$ versus method GB $56 \pm 7 \mu \mathrm{g} / \mu \mathrm{l}$, with a statistically significant difference $(\mathrm{P}<0.05)$ (Fig. 2). When 260/280 absorbance ratio was calculated for both to assess purity of DNA. Absorbance ratio was $1.92 \pm 0.13$ in GB, but, $1.6 \pm 0.17$ was encountered in GA, reflecting a degree of protein contamination in samples related to GA and a more pure form of DNA extracted from GB. On the other hand, following nested PCR reactions, 8 samples from GA failed to generate any PCR products.Amplification of $\beta$-giardin gene was only successful for 22 out of 30 samples of GA (73.3\%), 28 samples related to GB showed positive bands $(511 \mathrm{pb})(93.3 \%)$ with a statistically significant difference compared to GA $(\mathrm{P}<0.05)$ (Fig $2 \& 3$ ). In this way, application of sucrose density-gradient isolation method prior to DNA extraction seemed worthy in increasing the sensitivity of molecular amplification of Giardia parasite.

Table 1: Comparison between methods GA and GB as regard amount; yield of DNA and successful PCR amplification \%.

\begin{tabular}{|l|l|l|l|}
\hline Group & Amount of nucleic & $260 / 280$ absorbance ratio & \% of successful amplification \\
\hline (A) & $73 \pm 11 \mu \mathrm{g} / \mu \mathrm{l}$ & $1.6 \pm 0.17$ & $73.3 \%$ \\
\hline (B) & $56 \pm 7 \mu \mathrm{g} / \mu \mathrm{l}$ & $1.92 \pm 0.13$ & $93.3 \%$ \\
\hline
\end{tabular}

\section{Discussion}

The successful application of polymerase chain reaction (PCR) depends basically on the integrity, yield and purity of the isolated DNA (Barnard et al, 2011; Silkie and Nelsoon, 2009; Yu and Morrison, 2004).
Many elements in stool have inhibitory effect during molecular amplification such as bilirubin, lipids, mucus, haemoglobin, bile salts, phenolic compounds and complex polysaccharides. The presence of PCR inhibitors in fecal materials in the form, perhaps 
originating from dietary vegetable, in addition to low quality DNA of some samples are among factors affecting sensitivity of PCR. These failures could be due to the minority of DNA quantity in fecal samples that failed to counteract the effect of the inhibitors that would have co-refined with the nucleic acids (Molina et al, 2007; Minvielle et al, 2008; Babaei et al, 2008). Successful application of PCR-based methods depended on understanding and overcoming the limitations in proposed protocols (David et al, 2011).

To undermine PCR inhibition possibly generated from direct DNA extraction from the stool samples, sucrose density- gradient was used in this work for purification of the parasitic stages prior to amplification process. The method was previously used to purify Giardia parasite by Luchtel et al. (1980) to investigate its ultrastructure using electron microscopy. In Iran, Khosro et al. (2014) used sucrose floatation method to isolate G. lamblia parasite prior to study the genotypes 'variability. The previous authors recommended the method for successful removal of inhibitors prior to polymerization process. This may explain the high positivity in our samples diagnosed by PCR technique in GB which subjected to purification by sucrose density-gradient method. But, samples in GA subjected to direct extraction showed amplification failure in six samples proved positive when investigated in GB. So, sucrose density-gradient is inexpensive highly satisfactory purification method for $G i$ ardia cysts. Reagents used in sucrose density-gradient concentration technique are cheap, readily available and easily prepared. In this study, it helps in removal of most PCR inhibitors from stool denoted by the more pure form of DNA versus the high level of protein contamination of samples when direct DNA extraction were applied (despite o lower yield of recovered DNA). Besides, it lead to successful detection of $G$. intestinalis in human feces $93.3 \%$ of cases versus $73.3 \%$ when direct DNA extraction was applied.
Although sucrose density-gradient purification was adopted by some authors in their research work with various molarities of sucrose solutions (density 1.275 Minvielle et al, 2008; density 0.85m, Babaei et al, 2008), many other authors had adopted direct DNA extraction without sucrose density-gradient purification. To the authors' knowledge, this is the first study that compares the efficacy of sucrose density-gradient isolation method (when applied prior to nucleic acid extraction) versus the direct extraction of DNA from stool. Khosro et al. (2014) was not a comparative one, but use for better molecular results than direct extraction from stool samples. The effect of sucrose density- gradient on the yield and purity of the isolated DNA and successful nested PCR amplifications for detection of giardiasis in this work approved the proposition of other authors.

\section{Conclusion}

Molecular reactions often require not only particular DNA amount but also purity for optimum performance. Purified cysts in sucrose density-gradient isolation helped in better recovery of nucleic acid by reduction of bacteria and other contaminants that badly affects the quality of DNA. It proved to be an efficient and sensitive method for processing of problematic clinical samples and detection of $G$. intestinalis in human feces. Further studies are ongoing to achieve a real standardization for molecular assays, either for diagnostic or epidemiologic purposes.

\section{References}

Babaei, Z, Oormazdi, H, Akhlaghi, A, Rezaie, S, Razmjou, E, et al, 2008: Molecular characterization of the Iranian isolates of Giardia lamblia: application of the glutamate dehydrogenase gene. Iran J. Pub. Hlth. 37, 2:75-82.

Barnard, TG, Robertson, CA, Jagals, P, Potgieter, N, 2011: A rapid and low-cost DNA extraction method for isolating Escherichia coli DNA from animal stools. Afri. J. Biotechnol. 10, 8:1485-90.

Caccio, SM, Ryan, U, 2008: Molecular epidemiology of giardiasis. Mol. Biochem. Parasitol. 160:75-80.

Caccio, SM, Thompson, RCA, McLauchlin, J, 
Smith, HV, 2005: Unraveling Cryptosporidium and Giardia epidemiology. Trends Parasitol. 21: 430-7.

Chakarova, B, 2010: Comparative evaluation of the diagnostic methods for detection of Giardia intestinalis in human fecal samples. Trakia J. Sci. 8, 2:174-9.

Clark, CG, Diamond, LS, 2002: Methods for cultivation of luminal parasitic protists of clinical importance. Clin. Microbiol. Rev 15:329-41.

David, EB, Coradi, ST, Oliveira-Sequeira, TC G, Ribolla, PEM, Katagiri, S, et al, 2011: Diagnosis of Giardia infections by PCR based methods in children of an endemic area. J. Venom.Anim. Toxins Incl.Trop. Dis. 17, 2:209-15.

Escobedo, A, Cimerman, S, 2007: Giardiasis: a pharmacotherapy review. Expert. Opin. Pharmacother. 8:1885-902.

Gomes, JF, Hoshino-Shimizu, S, Dias, LC, Araújo, AJ, Castilho, VL, et al, 2004: Evaluation of a novel kit (TF-Test) for the diagnosis of intestinal parasitic infections. J. Clin. Lab. Anal. $18,2: 132-8$.

Goñi, P, Martín, B, Villacampa, M, García, A, Seral, C, et al, 2012: Evaluation of an immunochromatographic dip strip test for simultaneous detection of Cryptosporidium spp, Giardia duodenalis, and Entamoeba histolytica antigens in human faecal samples. Eur. J.. Clin. Microbiol. Infect. Dis 12:1544-7.

Khosro-Tappeht, KH, Manafi, G, Asgharzadeh, M, Manafi, F, 2014: Incidenceof Giardia lamblia Subspecies by PCR-RFLP in stool specimens of hospitalized children at Urmia Mutahhari Hospital, West Azerbaijan Province, Iran. J. Parasitol. 9, 4:541-7.

Lalle, M, Pozio, E, Capelli, G, Bruschi, F, Crotti, D, et al, 2005): Genetic heterogeneity at the b-giardin locus among human and animal isolates of Giardia duodenalis and identification of potentially zoonotic subgenotypes. Int. J. Parasitol. 35:207-13.

Luchtel, DL, Lawrence, WP, DeWalle, FB, 1980: Electron microscopy of Giardia lamblia cysts. Appl. Environ. Microbiol. 40, 4:821-32. Minvielle, MC, Molina, NB, Polverino, D, Ba- sualdo, JA, 2008: First genotyping of Giardia lamblia from human and animal feces in Argentina, South America. Mem. Inst. Oswaldo Cruz, Rio de Janeiro 103, 1:98-103.

Molina, N, Polverino, D, Minvielle, M, BasuaIdo, J, 2007: PCR amplification of triosephosphate isomerase gene of Giardia lamblia in formalin fixed feces. Rev. Latinoam Microbiol. 49: 5-10.

Nahavandi, KH, Fallah, E, Asgharzadeh, M, Mirsamadi, N, Mahdavipour, B, 2011: Glutamate dehydrogenase \& triose-phosphate-isomerase coding genes for detection and genetic characterization of Giardia lamblia in human feces by PCR and PCR-RFLP. Turk J. Med. Sci. 41, 2: 283-9.

Nantavisai, K, Mungthin, M, Tanariya, P, Rangsin, R, Naaglor, T, Leelayoova, S, 2007: Evaluation of the sensitivities of DNA extraction and PCR methods for detection of Giardia duodenalis in stool specimens. J. Clin. Microbiol, 45, 2:581-3.

Pelayo, L, Nuñez, L, Rojas, E, Hansen, B, Gjerde, H, et al, 2008: Giardia infections in Cuban children: Genotypes circulating in a rural population. Ann. Trop. Med. Parasitol. 102:58595

Plutzer, J, Ongerth, J, Karanis, P, 2010: $G i-$ ardia taxonomy, phylogeny and epidemiology: Facts and open questions. Int. J. Hyg. Environ. Hlth. 213:321-33.

Read, CM, Monis, PT, Thompson, RC, 2004: Discrimination of all genotypes of Giardia duodenalis at the glutamate dehydrogenase locus using PCR-RFLP. Infect. Genet. Evol. 4:125-30. Silkie, SS, Nelson, KL, 2009: Concentrations of host specific and generic fecal markers measured by quantitative PCR in raw sewage and fresh animal feces. Water Res. 43, 4860-71.

Traub, RJ, Monis, PT, Robertson, ID, 2005: Molecular epidemiology: a multidisciplinary approach to understanding parasitic zoonoses. Int. J. Parasitol 35:1295-307.

Yu, Z, Morrison, M, 2004: Improved extraction of PCR-quality community DNA from digesta and fecal samples. Bio-Techn. 36:808-12.

\section{Explanation of figures}

Fig. 1: (1a) Sample belongs to group (A), heavily contaminated with bacteria and fecal detritus, (1b) Sample after applying Sucrose density-gradient concentration technique. Many of these contaminants removed and cysts recovered finally.

Fig. 2a: Diagram represents average quantity of nucleic acid obtained by GA versus obtained by GB.

Fig. 2b: diagram represents successful amplification of $\beta$-giardin gene in group (A) versus in group (B).

Fig. 3: An ethidium bromide stained agarose electrophoresis showing Nested PCR product of G. lamblia. Lane M: DNA marker (100bp ladder). Lane 1: Positive case of giardiasis showing PCR product of expected size (511 bp). Lane 2: Positive control. Lane 3: Negative control. 

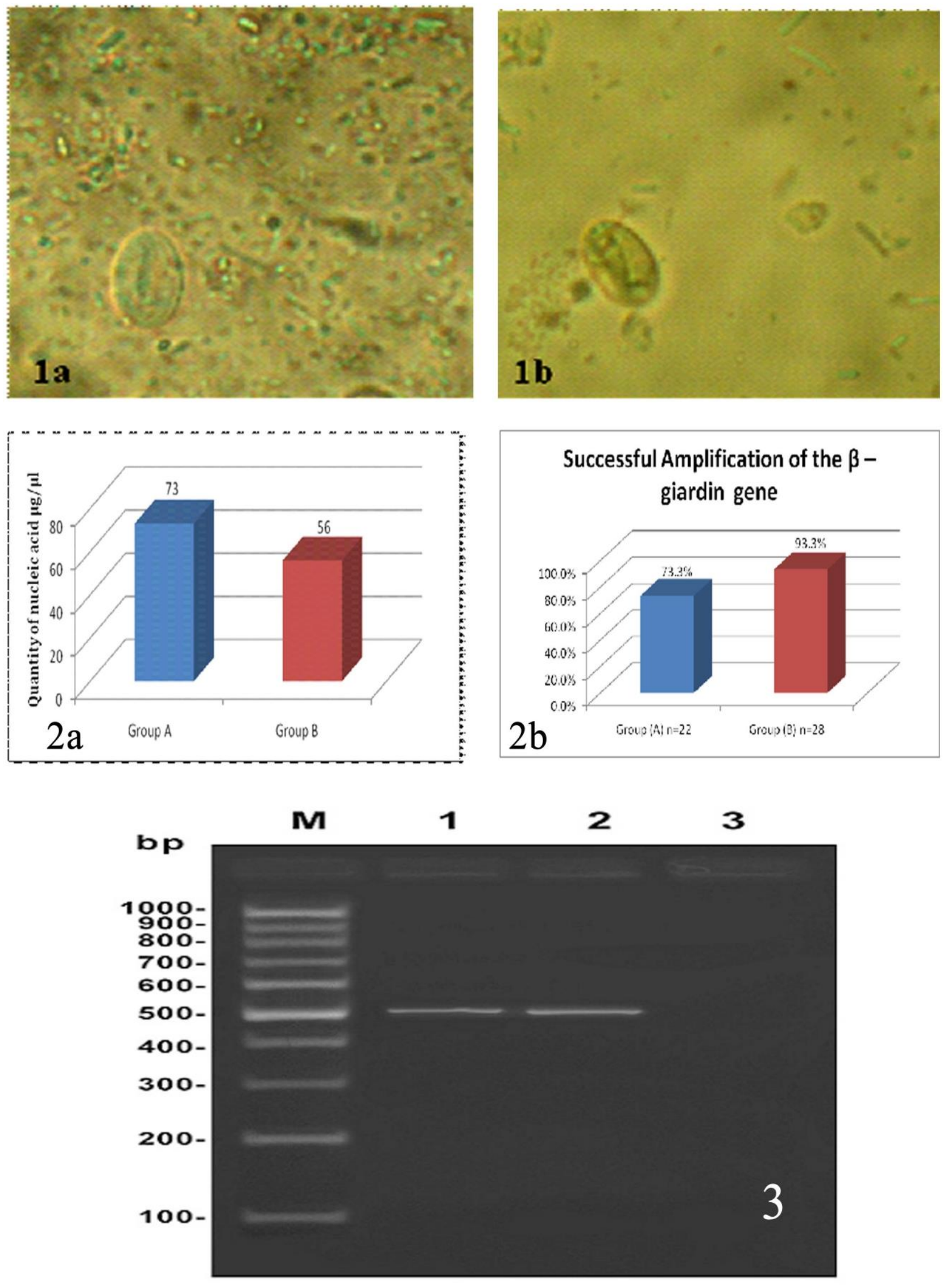